\title{
Clinical Application of Botulinum Toxin to Contact Granuloma and Vocal Nodule
}

\author{
Seung Won Lee (D) \\ Department of Otolaryngology-Head and Neck Surgery, Soonchunhyang University College of Medicine, Bucheon, Korea \\ 보툴리눔 독소를 이용한 성대육아종과 성대결절 치료 \\ 이 승 원 \\ 순천향대학교 의과대학 이비인후-두경부외과학교실
}

In the field of otolaryngology-head and neck surgery, botulinum toxins are widely used for the treatment of spasmodic dysphonia and vocal tremors. Recently, the applications of botulinum toxin have gradually expanded with time, to include vocal fold granuloma, mutational falsetto, bilateral vocal cord paralysis, and chemical reduction for arytenoid dislocation as an adjunctive modality. According to a nation-wide multicenter study conducted by the Korean Society of Laryngology, Phoniatrics and Logopedics for treatment modality of contact granuloma, among the various treatment modalities, botulinum toxin injection showed the highest response rate and lowest recurrence rate in both primary and refractory cases. Therefore, botulinum toxin could be reserved as a second-line treatment for contact granuloma in which the first treatment was not effective, but also could be used as a first-line treatment depending on the patient's and institution's situation. For recalcitrant nodules, injection of botulinum toxin into the bilateral thyroarytenoid muscle will reduce glottal contact force and result in a forceful chemical voice rest. In special situations, botulinum toxin injection could be one of the alternative treatment options for recalcitrant vocal nodules.

Keywords Granuloma; Dysphonia; Botulinum toxin.

\section{서 론}

이비인후과 영역에서 보툴리눔 독소는 주로 연축성 발성장애(spasmodic dysphonia) 의 증상 조절 목적으로 가장 많이 사용되고 있으나, ${ }^{1)}$ 이 외에도 성대육아종(vocal fold granuloma), 변성 발성장애(mutational falsetto), 양측 성대마비(bilateral vocal fold paralysis), 본태성 성대진전(essential vocal tremor), 피열연골 탈골의 정복(chemical reduction for arytenoid dislocation), 윤상인두 연하장애(cricopharyngeal dysphagia), 수술 후 침샘류(sialocele), 침샘비대에 의한 미용 문제 등, 이의 적응증 및 시술 빈 도가 빠른 속도로 증가하고 있다. ${ }^{2)}$
Received December 4, 2018

Revised April 6, 2019

Accepted May 20, 2019

Corresponding Author

Seung Won Lee, MD, PhD

Department of Otolaryngology-

Head and Neck Surgery,

Soonchunhyang University

College of Medicine,

170 Jomaru-ro, Bucheon 14584, Korea

Tel +82-32-621-5450

Fax+82-32-621-5016

E-mail Isw0922@schmc.ac.kr

ORCID iD

Seung Won Lee (D)

https://orcid.org/0000-0002-0468-8143

This is an Open Access article distributed under the terms of the Creative Commons Attribution Non-Commercial License (https://creativecommons.org/ licenses/by-nc/4.0) which permits unrestricted non-commercial use, distribution, and reproduction in any medium, provided the original work is properly cited. 


\section{본 론}

보툴리눔 독소는 이비인후과뿐 아니라, 성형외과, 안과, 재 활의학과, 신경과 등의 영역에서 광범위하게 사용되고 있다. ${ }^{3)}$ 주된 적응증으로는 안검연축(blepharospasm), 사시(strabismus), 근경련(muscle spasms), 상부 운동신경 증후군(upper motor neuron syndrome), 원발성 다한증(severe primary axillary hyperhidrosis), 경부 근긴장이상증(cervical dystonia), 만성 편두통(chronic migraine), 이갈이(bruxism), 식도 이완불능증(achalasia) 등의 기능적 장애와 사각턱(square jaw), 안면부 주름살(wrinkle) 등의 미용적인 영역이며, 그 적 용 범위와 사용 빈도가 점차 많아지고 있다. 이비인후과 영역 에서는 연축성 발성장애 치료 외에도 성대육아종(vocal fold granuloma), 치료 저항성 성대결절(recalcitrant vocal nodule), 변성기 발성장애(mutational falsetto), 양측 성대마비(bilateral vocal fold paralysis), 본태성 성대진전(essential vocal tremor), 윤상인두 연하장애(cricopharyngeal spasm), 피열 연골 탈골(arytenoid dislocation), 침샘류(sialocele), Frey syndrome, 안면마비 재활 등에 시도되고 있다. ${ }^{2}$ 본 논문은 치 료 저항성 성대 육아종과 성대결절에서의 보툴리눔 독소 사 용의 유용성에 관한 기술이다.

\section{치료 저항성 성대육아종(Refractory vocal fold granuloma)}

성대육아종은 피열연골의 성대 돌기(vocal process of arytenoid cartilage)면에 과증식성 육아조직(hypertrophic granulation tissue)이 자라나는 질환이다. 주로 환자가 '켁켁거리 는 것' 과 같은 성대접촉(hard glottal attack)에 의한 성대 돌기 내측의 염증, 궤양에 의해 발생하는 것으로 생각하고 있으나, 이 외에도 반복적인 헛기침, 인후두 역류, 반복적인 저음사용, 흡연, 후비루, 인후 감염 등과의 연관성도 제기되고 있다.5) 치 료 방법으로는 단순 관찰, 음성 치료, 스테로이드 흡입, 보툴리 눔 독소 주입, 수술적 제거, 심지어 방사선 치료와 같은 치료 방법이 극단적으로 넓어서, 치료 가이드라인이 정립되어 있지 않다. ${ }^{6,7)}$

2014년 대한후두음성언어의학회는 국가 단위의 다기관 공 동 연구를 진행하였다. 전국의 18 개 대학병원, 20 명 후두음성 전공교수의 참여하에 590 증례라는 세계 최대 규모의 성대육 아종 증례를 분석하여 치료 가이드라인을 제시하였다.

성대육아종의 치료 방법 중 음성 치료(voice therapy), 양성 자 펌프억제제 치료(proton pump inhibitor), 보툴리눔 독소 치료, 수술적 제거(surgical removal)는 통계적으로 유효한 치 료 효과를 보였으나, 수술적 치료는 추적 관찰 기간 중 높은
재발률을(37.1\%) 보여서 치료 방법으로 추천되지 않았다. ${ }^{8}$ 통 계적으로 유의하게 치료 효과가 있는 음성 치료, 양성자 펌프 억제제 치료, 보툴리눔 독소 치료 중 보툴리눔 독소 치료가 가장 좋은 반응률(response rate)과 낮은 재발률 소견을 보였 다(Table 1).

본 연구에 근거하여 대한후두음성언어의학회는 다음과 같 은 치료가이드 라인을 제시하였다. 성대육아종 환자에게 초 기 치료로 음성 치료 혹은 양성자 펌프억제제 치료를 시도해 보고, 치료 효과가 없거나, 추적 관찰 중에 육아종이 재발하는 경우에는 보툴리눔 독소 치료를 추천하였다. 하지만 병원 여 건 및 환자 개인 사정에 따라서 보툴리눔 독소 치료를 1차 치 료로 사용할 수 있다(Fig. 1).

성대로의 보툴리눔 독소의 주입 방법으로는 근전도하(laryngeal electromyography), 성대 주입술 방법(injection laryngoplasty technique), 혹은 전신마취 후 후두경 하 주입 등 의 방법으로 시행할 수 있다. 저자의 경우 국소마취하에 성대

Table 1. Long-term outcome according to treatment modality

\begin{tabular}{|c|c|c|c|}
\hline Treatment modality & p-value & $\begin{array}{c}\text { Exp (B) } \\
\text { odds ratio }\end{array}$ & $95 \% \mathrm{CI}$ \\
\hline \multicolumn{4}{|l|}{ Observation-references } \\
\hline Voice Tx & 0.023 & 6.566 & $1.301-33.134$ \\
\hline Antireflux Tx & 0.021 & 5.438 & $1.291-22.911$ \\
\hline Steroid inhalation & 0.425 & 1.889 & $0.396-9.013$ \\
\hline Botulinum toxin & 0.001 & 58.665 & $7.036-489.162$ \\
\hline Surgical removal & 0.068 & 4.943 & $0.887-27.553$ \\
\hline
\end{tabular}

Long-term outcomes were based on the endoscopic images at the last follow-up visit. Botulinum toxin demonstrated better response rate and lower recurrence rate among various treatment modality. Adapted from Lee et al. Laryngoscope 2014;124(5):1187-91. ${ }^{8)}$ Tx: treatment, CI: confidence interval

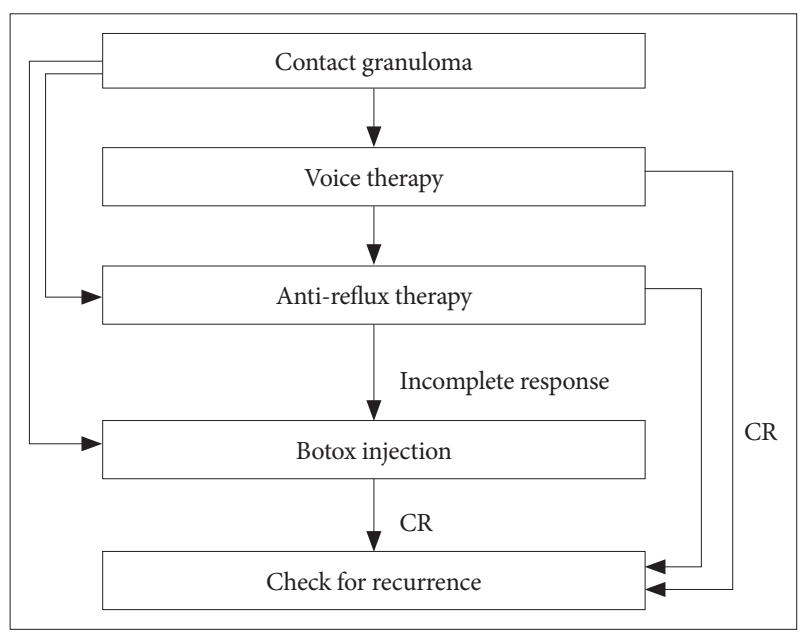

Fig. 1. Suggested treatment algorithm for the contact granuloma based on Korea national wide study. Adapted from Lee et al. Laryngoscope 2014;124(5):1187-91. ${ }^{8)}$ CR: complete remission. 


\section{JKSLP}

주입술 방법으로 양측 갑상피열근(thyroarytenoid muscle)에 보툴리눔 독소를 주입하는 방법을 선호한다(Fig. 2).' ${ }^{9}$ 이외에 도 병변측 갑상피열근(thyroarytenoid muscle)과 병변측 외 측 윤상피열근(lateral cricoarytenoid muscle)에 보툴리눔 독소를 주입하는 방법을 사용할 수도 있다. ${ }^{6}$

성대육아종 환자에서 보툴리눔 독소는 기존의 치료 방법에 비하여 확실한 효과의 우위와 낮은 재발률 등의 장점을 가진
다. 특히 약물 치료나 음성 치료에 반응하지 않는 치료 저항성 성대육아종 환자에서 과거에 시행하던 전신마취하 육아종 절제술에 비하여 국소마취하에 시행할 수 있는 장점이 있다. ${ }^{8}$

하지만, 보툴리눔 독소 주입 후 환자는 약 3 4주간의 약한 목소리와 간헐적인 사레 걸림과 같은 단점도 가지고 있음을 주지하여야 한다. ${ }^{9}$
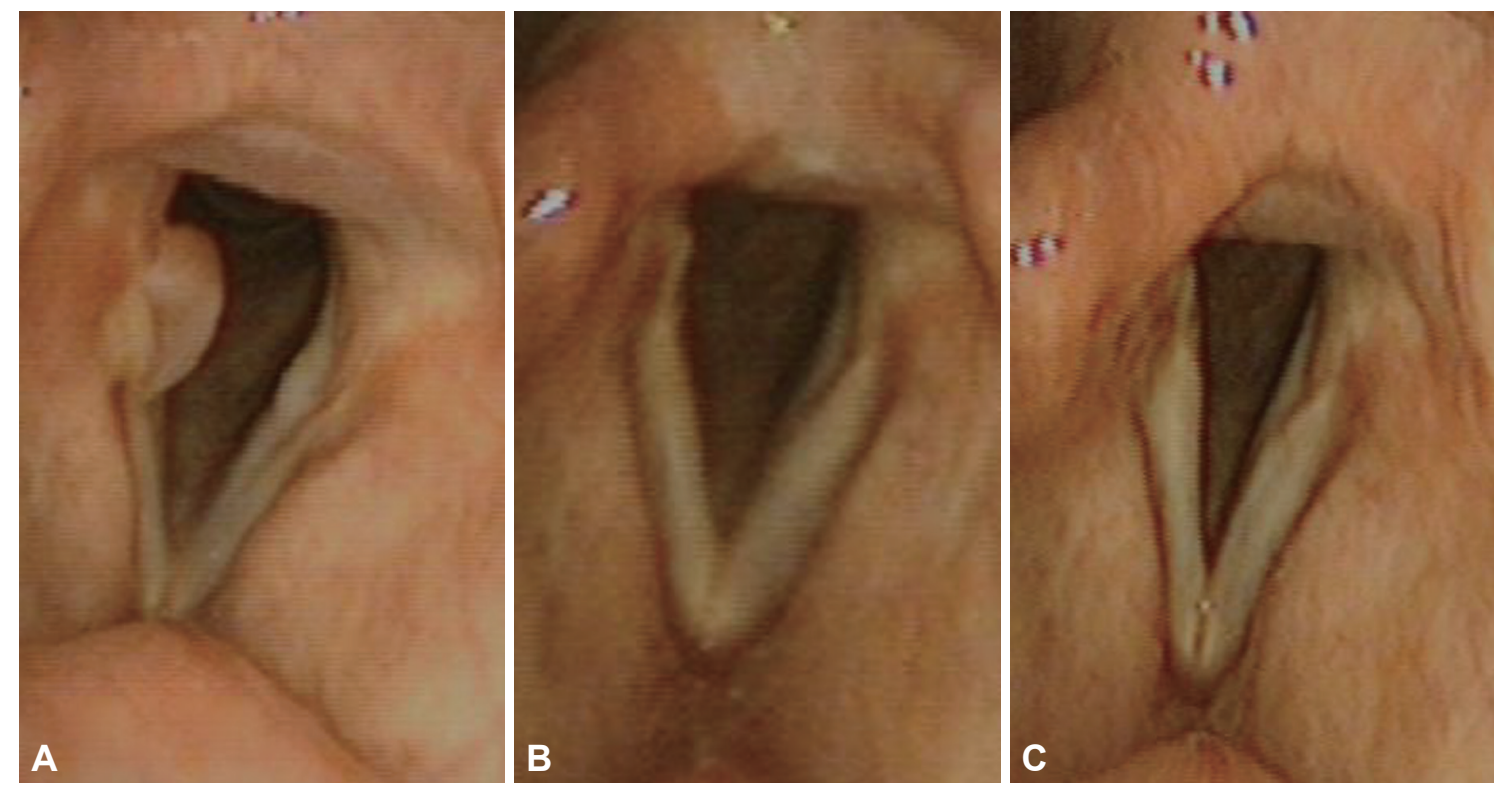

Fig. 2. Serial surgical photograph of right sided large typical contact granuloma following botulinum toxin injection. Complete remission was achieved only with botulinum toxin injection to bilateral thyroarytenoid muscle. Pre-botulinum toxin injection (A). Post- botulinum toxin injection 1 month (B). Post-botulinum toxin 2 months (C).
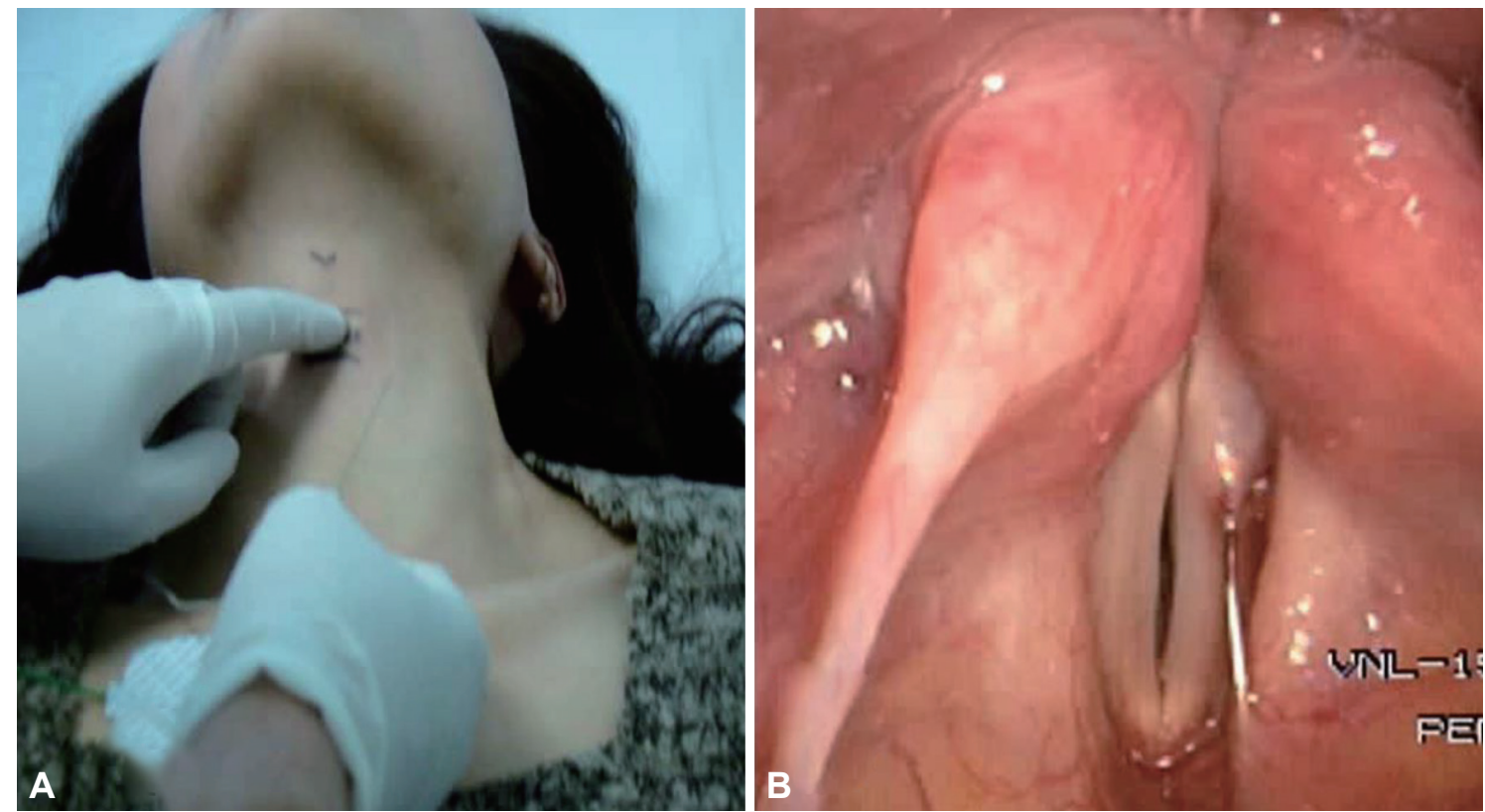

Fig. 3. Botulinum toxin delivery technique to thyroarytenoid muscle of recalcitrant vocal nodule patient. Laryngeal electromyography guided techniques (A). Injection laryngoplasty techniques under fiberscopy (B). 


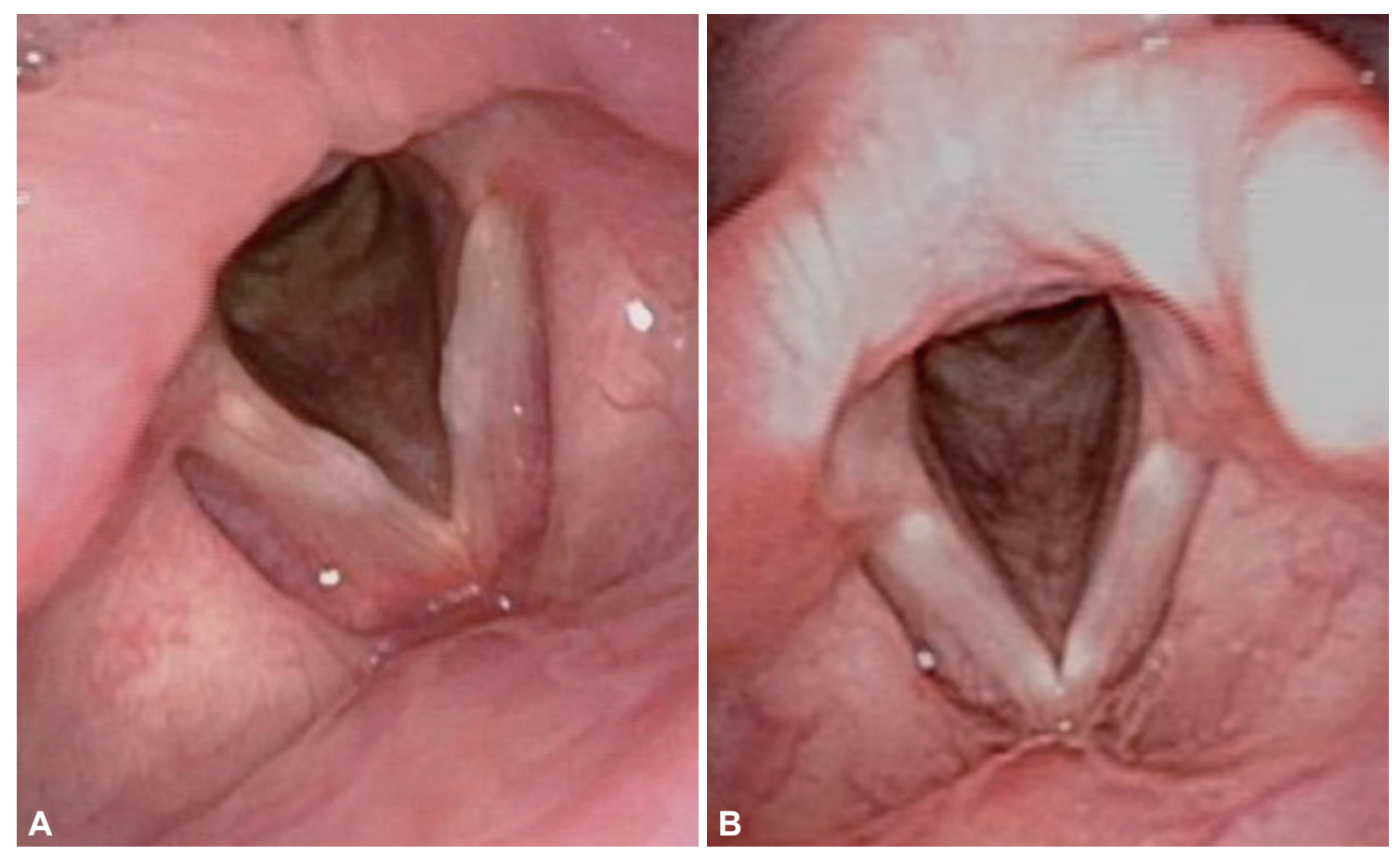

Fig. 4. Serial surgical photograph of vocal nodule patients following botulinum toxin injection.Pre-botulinum toxin injection (A). Post-botulinum toxin injection 1 month (B).

\section{치료 내성 성대결절(Recalcitrant vocal nodule)}

성대결절의 표준 치료인 음성 치료에 효과가 없거나, 환자 개 인 사정상 주기적인 음성 치료가 불가능할 경우, 전신마취하 후 두 미세 수술, 국소마취하 성대 스테로이드 주입술, 국소마취 하 후두 레이저 수술 등이 대안 치료가 될 수 있다.10,11) 하지만 이들 대안 치료 외에도 양측 성대근에 보툴리눔 독소를 주입 하는 방법이 또 다른 치료 수단이 될 수 있다(Figs. 3 and 4).

이는 성대근에 보툴리눔 독소를 주입하여 성대 접촉을 강 제적으로 억제하는 일종의 화학적 강제 음성 휴식(chemical voice rest)에 해당된다. ${ }^{12)}$ Allen과 Belafsky ${ }^{12)}$ 는 음성 치료에 반응하지 않는 성대 결절 환자에서 근전도하에 양측 갑상피 열근에 각각 $2.5 \mathrm{U}$ 의 보툴리눔 독소를 주입하여 성대결절의 완전 관해(complete remission)를 유도하여 성대결절의 새로 운 치료방법(novel approach)이라고 주장하였으나, 아직까지 이의 유용성에 대해서는 검증이 필요할 것으로 사료된다.

성대근 내 보툴리눔 독소술의 장점은 음성 치료에 반응하지 않는 성대 결절 환자에서 전신마취하 후두 미세술을 피할 수 있다. 하지만, 보툴리눔 독소의 성대근 내 주입에 따른 3 4주 간의 쉰 목소리와 사레 걸림을 감수해야 하는 단점이 있다.

보툴리눔 독소를 이용한 강제 음성 휴식은 기존의 음성 치료, 성대근 내 스테로이드 주입술에 비하여 아직 안정성 및 임상 적 유용성이 확실하게 검증되었다고 할 수 없고, 현재로서는 다른 치료법의 장점과 단점을(benefit과 harm) 비교하였을
때, 특별한 우위를 가졌다고 할 수 없다.

\section{결 론}

성대육아종의 치료를 위해 음성치료, 수술적 제거, 스테로 이드 흡입, 성대근 내 보툴리눔 독소 주입술, 양성자 폄프억제 제, 경과 관찰 등 다양한 방법이 시행되어 왔다. 2014년 대한 후두음성언어의학회가 주관한 후향적 다기관 연구에서는 음 성치료, 양성자 펌프억제제, 보툴리눔 독소 주입술 등이 유의 한 효과를 보이는 것으로 나타났다. 최근 들어 성대 육아종에 대한 기존의 치료법들 중 보툴리눔 독소치료법으로의 패러다 임 변화(paradigm shift)가 이루어지고 있는 상태이다. 성대결 절의 치료를 위한 보툴리눔 독소 주입술은 음성치료에 효과 가 없는 경우 대안 치료(alternative treatment)로서 시도해볼 수 있다.

중심 단어: 육아종, 음성변화, 보툴리눔 독소.

Acknowledgments

None.

Conflicts of Interest

The author has no financial conflicts of interest. 


\section{REFERENCES}

1. Blitzer A, Brin MF. Laryngeal dystonia: a series with botulinum toxin therapy. Ann Otol Rhinol Laryngol 1991;100(2):85-9.

2. Blitzer A, Sulica L. Botulinum toxin: basic science and clinical uses in otolaryngology. Laryngoscope 2001;111(2):218-26.

3. Gibbs SR, Blitzer A. Botulinum toxin for the treatment of spasmodic dysphonia. Otolaryngol Clin North Am 2000;33(4):879-94.

4. Hoffman HT, Overholt E, Karnell M, McCulloch TM. Vocal process granuloma. Head Neck 2001;23(12):1061-74.

5. Carroll TL, Gartner-Schmidt J, Statham MM, Rosen CA. Vocal process granuloma and glottal insufficiency: an overlooked etiology? Laryngoscope 2010;120(1):114-20.

6. Orloff LA, Goldman SN. Vocal fold granuloma: successful treatment with botulinum toxin. Otolaryngol Head Neck Surg 1999;121(4): 410-3.

7. Mitchell G, Pearson CR, Henk JM, Rhys-Evans P. Excision and low- dose radiotherapy for refractory laryngeal granuloma. J Laryngol Otol 1998;112(5):491-3.

8. Lee SW, Hong HJ, Choi SH, Sun DI, Park YH, Lee BJ, et al. Comparison of treatment modalities for contact granuloma: a nationwide multicenter study. Laryngoscope 2014;124(5):1187-91.

9. Damrose EJ, Damrose JF. Botulinum toxin as adjunctive therapy in refractory laryngeal granuloma. J Laryngol Otol 2008;122(8):824-8.

10. Lee SW, Park KN. Long-term efficacy of percutaneous steroid injection for treating benign vocal fold lesions: a prospective study. Laryngoscope 2016;126(10):2315-9.

11. Woo JH, Kim DY, Kim JW, Oh EA, Lee SW. Efficacy of percutaneous vocal fold injections for benign laryngeal lesions: prospective multicenter study. Acta Otolaryngol 2011;131(12):1326-32.

12. Allen JE, Belafsky PC. Botulinum toxin in the treatment of vocal fold nodules. Curr Opin Otolaryngol Head Neck Surg 2009;17(6):427-30. 